\title{
Uma análise económica da Provincia de Mato Grosso na primeira metade do século XIX
}

\author{
Ney Iared Reynaldo*
}

O presente artigo visa analisar a conjuntura econômica da Província de Mato Grosso, na primeira metade do século XIX. Demonstrando a necessidade da reorganização e do aproveitamento de diversos produtos extrativistas, que uma vez utilizados pelas populações da província, estariam superando a dependência dos produtos vindos de fora, em substituição aos consumidos e produzidos localmente, cuja atividade contribui para uma possível acumulação e vinculação aos mercados regional e nacional.

Palavras-chave: Província de Mato Grosso. Produtos extrativistas. Mercado regional

This article aims to analyze the economic situation of the province of Mato Grosso, in the first half of the 19th century. Demonstrating the need for reorganization and the utilization of various extractive products, once used by the populations of the province, would be overcoming the dependency of products from outside, replacing
A independência do Paraguai e o isolamento político em que foi envolvido esse país nas primeiras décadas do século XIX trouxeram reflexos significativos para a economia da Província de Mato Grosso. Principalmente as relações comerciais na fronteira e a comunicação com outros mercados provinciais foram afetadas. Para que a Província saísse da estagnação, buscaram-se alternativas, como o desenvolvimento de uma economia mais autossuficiente, que diminuísse a sua dependência das importações de produtos, seja do próprio país, seja do exterior.

\footnotetext{
* Docente do Departamento de História e Ciências Econômicas do Campus Universitário de Rondonópolis, Universidade Federal de Mato Grosso.neyhis@yahoo.com.br
} 
the consumed and produced locally, whose activity contributes to a possible accumulation and linking regional and national markets.
Keywords: Spain Almeria province of Mato Grosso. Extractive products. Regional market

\section{Introdução}

$\mathrm{N}$ o intuito de verificar as potencialidades econômicas da província, o presidente José Saturnino da Costa Pereira (1823-1834) encarregou o sargento-mor, Engenheiro Luiz D'Alincourt (1787-1841), entre os anos de 1825 e 1830, de fazer um amplo levantamento estatístico acerca dos recursos econômicos existentes no interior mato-grossense. Em um dos trabalhos publicados pelo engenheiro militar, encontra-se uma descrição detalhada da fauna e da flora mato-grossenses e das suas potencialidades econômicas ${ }^{1}$.

Em seu relato, o sargento-mor alertou que Mato Grosso apresentava grande dependência da importação de alimentos de outras províncias, o que retirava recursos de sua economia e reduzia as possibilidades de sua arrecadação interna. Alertou para a necessidade da substituição de alguns produtos que eram importados, argumentando que seus preços poderiam ser reduzidos com sua produção parcial própria da Província ${ }^{2}$. Propôs também ao Governo tornar conhecidos alguns produtos que já eram ali produzidos, a fim de que os comerciantes os explorassem economicamente.

Nesse relato, encontramos diversos exemplos desses produtos. Ao visitar distintas localidades da Província na sua parte sul, no vale do rio Paraguai, D'Alincourt constatou boa produção de alimentos, como: feijão, arroz, milho e mandioca, encontrados com fartura, pois "só bastava aproximar-se dos terrenos alagados e colhê-los, o suficiente para atender ao consumo interno e o restante favorecia sua exportação" .

\footnotetext{
${ }^{1}$ Em seu Relatório final, D'Alincourt assinalou recursos naturais, que ainda estariam por ser explorados pela sociedade mato-grossense. D'ALINCOURT, Luiz. Rezultados dos trabalhos e indagações statisticas da província de Matto-Grosso. Cuyabá: [s.n.], 1828. p. 60.

${ }^{2}$ D'ALINCOURT, Luiz, Officios sobre a estatística, defesa e administração da Província de Mato Grosso de 1824 a 1826. Revista do Instituto Histórico e Geográfico Brasileiro, Rio de Janeiro, t. 20, 1857, p. 41.
}

${ }^{3}$ Idem., p. 48. 
Durante suas investigações, Luiz D'Alincourt fez um verdadeiro inventário das potencialidades mato-grossenses, concluindo que, nas áreas percorridas do vale do rio Paraguai, podia ser encontrada grande disponibilidade de recursos da flora natural ${ }^{4}$. Chegou a sugerir novas formas de aproveitamento, indicando os meios necessários para transformar estas matérias-primas em produtos de plena aceitação no mercado internacional. Esse é o caso da descoberta, no interior das florestas da região, de grande quantidade de salsaparrilhas, anil e baunilha, matérias-primas que eram importadas por Mato Grosso e que poderiam, se estimuladas pelo Governo e pela iniciativa particular, ser exploradas na Província 5 .

\section{As indústrias extrativistas}

Apesar de haver essa diversidade de recursos da flora natural e produtos agrícolas a serem explorados na Província de Mato Grosso, foram as atividades extrativistas de jazidas minerais que primeiro receberam a atenção de governantes e investidores. Visavam à substituir as importações mas, principalmente, a incrementar as exportações da província aos demais mercados do Brasil.

O Anuário Econômico da Província de Mato Grosso, publicado em 1852, na administração de Augusto João Manoel Leverger, entende indústrias extrativistas como sendo o conjunto de matérias-primas existentes no interior da Província que, uma vez aproveitado, poderá gradativamente substituir as importações de outras províncias, reduzindo, com isso, a sua dependência desse tipo de comércio. Este documento classifica as indústrias extrativistas em duas categorias: mineral e vegetal ${ }^{6}$. A primeira, tradicionalmente explorada em Mato Grosso desde a época colonial, teve suas atividades reiniciadas na segunda metade do século XIX, apesar da falta de recursos técnicos na sua exploração e a segunda permitia a introdução de novas matérias-primas, como a poaia, no mercado internacional.

\footnotetext{
${ }^{4}$ D'ALINCOURT, Luiz, Resumo das explorações feitas pelo engenheiro [...] desde o registro de Camapuã até a cidade de Cuyabá (25 jun. 1826). Instituto Histórico e Geográfico Brasileiro, Rio de Janeiro, 1857, p. 66-78,

${ }^{5} \mathrm{D}^{\prime}$ ALINCOURT, Luiz. Rezultados..., Op. cit., p. 65.

${ }^{6}$ ANUÁRIO Econômico da Província de Mato Grosso, Rio de Janeiro, n. 1, v. 1, de ago. 1852, p. 75-77.
} 


\subsection{As indústrias extrativistas minerais 1.1.1 Diamantes eouro}

O desenvolvimento da mineração nesse período é exposta por quase todos os presidentes da Província de Mato Grosso ${ }^{7}$. Essa preocupação permitiu à economia provincial novos investimentos de capitais, tanto nacionais como estrangeiros, no sentido de reativar as antigas atividades extrativistas de jazidas minerais, relacionadas à extração de diamantes, ouro e pedras preciosas ${ }^{8}$. Com relação ao valor dos diamantes, Corrêa Filho assegura que os preços "nos primeiros tempos só alcançavam 30 a $20.000 \$$ a oitava" e chegaram, em 1830, a "320\$000 no lugar de extração9. Ao todo (diamante e ouro), houve um razoável aumento da produção entre os anos de 1824 e 1839, bem como uma valorização em onça ${ }^{10}$ no mercado externo totalizando uma receita de $156 \$ 000^{11}$. (ver tabela 1$)$.

Tabela 1 - Produção mineral da Província de Mato Grosso

\begin{tabular}{|c|c|c|c|}
\hline Minério & Ano & Quantidade $(\mathrm{Kg})$ & Valor (em mil reis) \\
\hline Diamantes & 1824 & 1.800 & $58 \$ 000$ \\
\hline Ouro & 1839 & 3.781 & $98 \$ 000$ \\
\hline
\end{tabular}

Fonte: Dados coletados nos relatórios econômicos das finanças da Província, entre os anos de 1824 e 1854. Localização: Arquivo Público do Estado de Mato Grosso. Lata F, Pasta VIII.

A tabela acima aponta para um crescimento da produção de diamantes e ouro no período em questão. Buscando recuperá-la, em 7 de junho de 1852, foi autorizada, na Corte, a formação de uma Companhia de Mineração, que tinha por objetivo explorar, para exportação, as jazidas de Mato Grosso ${ }^{12}$. Em 1853, os agentes da Companhia já trabalhavam no vale do rio Paraguai. Para isso, o

\footnotetext{
${ }^{7}$ WAEHNELADT, Rodolfo. Explorações da Província de Matto-Grosso. Instituto Histórico e Geográfico Brasileiro, Rio de Janeiro, t. 27, pt. I, 1864, p. 202.

${ }^{8}$ FONSECA, José Gonçalves da. Notícia da situação da província de Mato Grosso: estado de uma e outras minas e novos descobrimentos de diamantes, ouros e pedras preciosas. Instituto Histórico e Geográfico Brasileiro, Rio de Janeiro, v. 29, n. 15, 1866, p.57-79.

${ }^{9}$ CORRÊA FILHO, Virgílio. A cata de ouro e diamantes. Rio de Janeiro: Paulo Pongetti, p. 51.

${ }^{10}$ Onça - Antiga medida de peso equivalente 1/16, ou em certos casos, 1/14 do arrátel. Eram aproximadamente 28,7 gramas.

${ }^{11}$ Idem., p. 196.

${ }^{12}$ Relatório da Companhia de Mineração da Província de Mato Grosso, dados referentes à extração de diamantes entre os anos de 1852 e 1853. Typ Mendes, Cuiabá, 11 de maio de 1853, p. 95.
} 
Governo Provincial ordenou que fossem cedidos cem escravos para realizar as tarefas de extração. Apesar da falta de tecnologia e de investimentos privados complementares, essa Companhia conseguiu ampliar as áreas de exploração e obter ganhos consideráveis ${ }^{13}$.

A exploração nas áreas auríferas necessitava, como já foi dito, de tecnologia, pois o ouro já não era encontrado à beira dos rios, e essas Companhias tinham recursos suficientes para levar adiante os trabalhos necessários. Em 1854, o presidente da Província Augusto Leverger enfatizava as vantagens que a instalação dessas Companhias poderia trazer para Mato Grosso,

Realisada que fosse a $1^{\text {a }}$, ha toda a rasão de, que outros serião o exemplo, convidadas pelos lucros que devem recolher, entretanto que serião de summa utilidade, para a prosperidade da Província, pelos diversos interesses que lhe darião, inclusive o addiantamento da industria $[\ldots]^{14}$.

Nesse mesmo ano, o Governo Provincial de Mato Grosso também investiu na mineração, através do Decreto n. 132, de 15 de maio, criando a Administração Provincial dos Terrenos Diamantinos ${ }^{15}$. Com isso, expôs o desencontro entre as ações dos governos imperial e provincial. Nesse sentido, no Relatório Extraordinário de 1854, Augusto Leverger colocava em dúvida os relatórios apresentados pela administração da Companhia de Mineração, que, segundo ele, não eram claros em suas conclusões, e "[...] deixava muita margem de dúvidas, sobretudo, quanto à quantidade de pedras extraídas e seu valor comercializado na região"16.

${ }^{13}$ Relatório do presidente da Província de Mato Grosso o Capitão de Mar e Guerra. LEVERGER, Augusto João Manoel. [Relatório] 1852 maio 3, Abertura Sessão Ordinária da Assembléia Legislativa Provincial [manuscrito] Cuyabá. Cuiabá, Typ. do Echo Cuiabano, 1853. f. 7.

${ }^{14}$ Relatório do Presidente da Província de Mato Grosso o Capitão de Mar e Guerra. LEVERGER. Augusto João Manoel. [Relatório] 1854 maio 3, Abertura da Sessão Ordinária da Assembléia Legislativa Provincial [manuscrito] Cuyabá, Typ. do Echo Cuiabano. f. 21.

${ }^{15}$ ANUÁRIO da Companhia Mineradora de Mato Grosso, 1853. Cuiabá: [s.n.], 1854. p. 42-51. Localização: Biblioteca do Arquivo Publico do Estado de Mato Grosso.

${ }^{16}$ Essa suspeita o levou, em 1852, a nomear o Coronel João Joaquim de Siqueira Pinto para o cargo de diretor-geral da Companhia de Mineração, o qual apresentou resultados bem diferentes sobre a produção mineral. Relatório do Presidente da Província de Mato Grosso o Capitão de Mar e Guerra, Augusto João Manoel Leverger, na abertura da Sessão Ordinária da Assembléia Legislativa Provincial, em 3 de maio de 1854, Cuiabá: Typ. do Echo Cuiabano, 1854. p. 122. 
Barrozo $^{17}$, ao estudar essa produção mais recentemente, aponta que o diamante mato-grossense experimentou maior declínio no período, possivelmente por causa das novas descobertas das minas baianas ${ }^{18}$. A pressão exercida pela concorrência dos diamantes, aí produzidos em grande quantidade, fez com que houvesse queda de seu preço no cenário internacional e, por conseguinte, uma diminuíção da exploração na Província, o que não significa que as pequenas quantidades de diamantes encontradas em Mato Grosso não fossem rentáveis ${ }^{19}$. Neste documento apresentado pelo comerciante Baptista Prudêncio de Almeida ao presidente da Província de Mato Grosso, Augusto Leverger,

Os preços que nos primeiros tempos só alcanzavam $30 \$$ a $40 \$$ a oitava e na época que discrevo chegou a vender-se no logar da extração a 320\$000. Depois, ocorreu a fatal baixa dos preços dos diamantes pela abundância do Sincorá, na Bahia, chegando a descer aqui nos annos de 1847 a 1850 a menos de $10 \$ 000$ a oitava ${ }^{20}$.

Podemos observar o prejuízo que ocasionou o achado de diamantes na Bahia, já que a grande oferta fez os preços diminuírem consideravelmente. $\mathrm{O}$ auge da produção das minas de ouro da Província, verificado nas primeiras décadas do século XIX, apresentou bons resultados. O minério era encontrado em grande quantidade na beira dos rios e em minas profundas, por isso se esgotou rapidamente. Combinando ambição, audácia e aventura, garimpeiros e autoridades políticas passaram a organizar expedições para outras paragens em busca do metal precioso.

Visando a organizar a exploração de ouro na Província, a partir de 1854, o Governo Provincial passou a calcular o Imposto de Extração Aurífera, que ficou sob o controle da reeditada Casa de Fundição em Cuiabá, vinculada à Secretaria de Fazenda. Nesse sentido, Borges ${ }^{21}$, observa que a partir de então, a mineração

\footnotetext{
${ }^{17}$ BARROZO, João Carlos. Em busca da pedra que brilha como estrela: um estudo sobre o garimpo e os garimpeiros do alto Paraguai: 1992. f. 182. Tese. (Doutorado em História). Universidade Estadual de São Paulo, São Paulo. 1992.

${ }^{18}$ Idem,

${ }^{19}$ Ver RONCO, Adriana Patrícia. O Desenvolvimento economico de Mato Grosso (1850-1902). 2006. f. 44. Tese (Doutorado em Economia). Universidade Federal Fluminense, Niterói, 2006.

${ }^{20}$ Informações de João Baptista Prudêncio de Almeida, apresentadas ao Presidente da Província, Augusto João Manoel Leverger. Citado por CORRÊA FILHO, Virgílio. A cata ..., Op. cit., p. 25.

${ }^{21}$ BORGES, Fernando Tadeu de Miranda. Do extrativismo à pecuária: algumas observações sobre
} 
de ouro apresentou melhora considerável do ponto de vista fiscal na Província de Mato Grosso ${ }^{22}$. Segundo o fiscal de rendas da Província, Francisco Torquato de Andrada, parte dos recursos arrecadados pela exploração do ouro e a entrada de investimento privado póssibilitaram a importação pelo rio Paraguai de maquinários específicos para exploração de minas de profundidade, localizadas na região de Cuiabá e no vale do rio Paraguai ${ }^{23}$.

Embora os resultados apresentados nos relatórios oficiais, registrassem apenas 77,8 quilos de ouro, entre os anos de 1852 e 1854, considerando apenas a extração das minas no vale do rio Paraguai, este número demonstrava que a exploração aurífera não foi abandonada e que as explorações em busca de ouro continuaram $^{24}$.

\subsubsection{Outros minerais: ferro, cobree manganes}

A Província de Mato Grosso possuía várias jazidas de minerais não preciosos, algumas de extração viável. No intuito de maior aproveitamento dessa diversidade, o Governo Provincial autorizou, à época, a exploração das jazidas de ferro, cobre e manganês existentes nas minas junto ao rio Paraguai. O geólogo Rodolfo Waeneldt, em suas andanças pela Província descobriu que ao lado dos minérios de ferro, cobre e manganês se achavam grandes quantidades de quartzo e calcário ${ }^{25}$.

Para isso, foi organizada uma sociedade composta por acionistas de comerciantes de Cuiabá e Corumbá, dirigida pelo Dr. Luis Alberto da Cunha Alves Ventorille e Alfredo Feitosa da Silva Ribeiro. Essa sociedade, depois de explo-

a história econômica de Mato Grosso 1870 a 1930. Cuiabá: Genus, 1991.

${ }^{22}$ Idem

${ }^{23}$ Dados levantados junto a Coletoria de Rendas da Província de Mato Grosso, 22 de abril de 1854. Localização: Arquivo Publico do Estado de Mato Grosso. Pasta 4. Lata E (Coletoria de Rendas).

${ }^{24}$ GARCIA, Domingos Sávio da Cunha. Mato Grosso (1850-1889): uma Província na fronteira do Império. 2001. f. 25. Dissertação (Mestrado em História). Universidade Estadual de Campinas, Campinas, 2001.

${ }^{25}$ WAEHNELADT, Rodolfo. Op. cit., p. 186. 
rar as minas situadas no rio Paraguai, logo foi dissolvida ${ }^{26}$. O próprio Augusto Leverger, em 1853, informava à Assembléia Provincial sobre "a existência de outras jazidas minerais na Província"27.

\subsubsection{Pedras preciosas}

Para que as jazidas minerais pudessem continuar a ser mais exploradas, Augusto Leverger decidiu incentivar também a exploração de pedras preciosas. Por meio da Resolução n. 15 de 21 de maio de 1854, autorizou o comerciante inglês Peter W. H. Montenegro a extrair pedras de esmeraldas pelo prazo de vinte anos. Para isso, Montenegro deveria pagar um imposto de $10 \%$ sobre o valor do minério extraído. Seu investimento deveria ser em torno de 50 mil libras esterlinas. E se, no término de dois anos, não começassem os trabalhos, a concessão poderia ser cancelada ${ }^{28}$.

Como o interesse pela exploração de minério ia além dos limites e interesses provinciais, o Governo da Província de Mato Grosso concedia autorização, em diversas oportunidades para a exploração de pedras preciosas de valor de mercado, principalmente de esmeralda, águas marinhas e turquesas ${ }^{29}$, na Província, mediante pagamento por esse privilégio. A esse respeito, informava o presidente da Província de Mato Grosso à Assembléia Legislativa.

Tem o Governo desta Província feito diversas concessões da datas de exploração mineral, notadamente, de pedras preciosas, pelo preço comprado por cada metro quadrado é de 5 reis, além do imposto de 5 por cento sobre o produto da mineração, o que é exhorbitante, vindo-se a pagar, além dos $5 \%$ sobre o produto líquido, cerca de 70 contos de reis por cada 100 datas minerais ${ }^{30}$.

${ }^{26}$ LEVERGER, Augusto João Manoel. [Relatório] 1851 maio 3, na Abertura da Sessão Ordinária da Assembléia Legislativa Provincial [manuscrito] Cuyabá. Cuiabá, Typ. do Echo Cuiabano, 1853. f. 91.

${ }^{27}$ LEVERGER, Augusto João Manoel. [Relatório] 1853 maio 3..., op. cit.. f. 39.

${ }^{28}$ WAEHNELADT, Rodolfo. Op. cit., p. 191.

${ }^{29}$ MOUTINHO, Joaquim Ferreira. Notícia sobre a província de Mato Grosso: seguido de roteiro de viagem e de sua capital a São Paulo. São Paulo: Tipografia Henrique Schroeder, 1889, p. 69.

${ }^{30}$ LEVERGER, Augusto João Manoel. [Relatório] 1853 ago 14, na Abertura da Sessão Ordinária da Assembléia Legislativa Provincial [manuscrito] Cuyabá. Cuiabá, Typ. do Echo Cuiabano, 1854. f. 101. 
A razão que levou a intervenção do Governo da Província a organizar e fiscalizar a exploração destas pedras preciosas se dava devido ao seu elevado contrabando para fora da Província, sobretudo, pela fronteira com o Paraguai ${ }^{31}$. Segundo Corrêa Filho, "muitas pedras de valor de Mato Grosso entravam clandestinamente no mercado platino, pelo rio Paraguai" 32 .

\subsubsection{Sal}

Segundo Beauchair (1993), o sal era um produto importante para Mato Grosso, a medida que era utilizado, na conservação de alimentos ${ }^{33}$. Sendo o sal produzido próprio para o consumo humano e de boa qualidade, sua extração se expandiu por todo o vale do rio Paraguai. Esse produto era comprado nas províncias do Rio de Janeiro e São Paulo a preços elevados, pagando-se até $100 \$ 000$ (cem mil contos de réis) o alqueire ${ }^{34}$.

As primeiras salinas naturais, encontradas no século XVIII, foram as de Almeida, as de Jaúru e as de Formosa, mas a sua produção não cobria as necessidades de Mato Grosso, razão pela qual se tornava imprescíndivel comprar o sal às casas comerciais. O sal marinho era vendido, na Província, a um alto preço $\mathrm{O}^{35}$.

A exploração das salinas se manteve durante muito tempo; novos locais foram descobertos e anexados às áreas de extração. Quando, em 1824, D`Alincourt percorreu a parte meridional da Província, assegurou que, entre Camapuã e Miranda, existia grande quantidade de sal. Essa situação não contribuiu para que se suspendessem as importações de sal; pelo contrário, entre os anos de 1825 e

\footnotetext{
${ }^{31}$ Livro de Cobrança Executivo de Impostos devido à Fazenda Provincial, Cuiabá, 1854. Localização: Arquivo do Ministério da Fazenda sob custódia do Núcleo de documentação e Informação Regional. Lata D - 1854, Cuiabá: Universidade Federal de Mato Grosso.

${ }^{32}$ CORRÊA FILHO, Virgílio. Subsídio para o histórico da Mineração em Mato Grosso. Revista do Instituto Histórico e Geográfico de Mato Grosso, Cuiabá, tomo 15, n. 11, v. 4, 1926, p. 22.

${ }^{33}$ BEAUCHAIR, Geraldo de. A construção da economia nacional (1822-1860). Tese (Doutorado em Economia). 1993, f. 30. Universidade Federal Fluminense, Niterói, 1993.

${ }^{34}$ Cf. CAMPESTRINI, Hildebrando; GUIMARÃES, Acyr Vaz. História de Mato Grosso do Sul. Campo Grande: Tribunal de Justiça de Mato Grosso do Sul, 1991.

${ }^{35}$ HOLANDA, Sérgio Buarque de. Monções. São Paulo: Editora Alfa-Omega, 1945, p. 116.
} 
1826, havia chegado sal marinho pelo valor de importação de 5.950\$000, posteriormente vendido ao preço de $28 \$ 800$ o alqueire ${ }^{36}$. Em 1848, o presidente da Província, Manoel Alves Ribeiro (1843-1848), dava um alentador informe acerca da extração de sal:

Tendo alguns individuos descido o rio Paraguay com intento de aproveitar das abundantes salinas que existem abaixo da Lagoa Negra, procurou a Presidência informar-se do Comandante Geral do Baixo Paraguay da quantidade de sal que se tem sido fabricado, e teve em resposta de 9 de março último a lisongeira noticia que desde outubro do anno passado até aquella data se havia fabricado 2.232 alqueires de sal, gênero de primeira necessidade, que lhe comprado nesta província, como sabeis, por mui grande preço em razão da dificuldade de transportar-lo de beira $\operatorname{mar}^{37}$.

Essa notícia contribuiu para aumentar o interesse pela extração do sal. Descobertas as salinas situadas no Baixo Paraguai, a produção alcançou valores muito importantes, o que levou o presidente da Província o Major Joaquim José de Oliveira (1848-1849), a afirmar que: "tem-se fabricado uma quantidade considerável de sal comum, de maneira que, se a produção deste gênero não diminuir, a sua importação da Província do Rio de Janeiro deve cessar inteiramente" ${ }^{38}$. A produção se manteve constante, sucesso que permitiu, não já anular, mas sim diminuir consideravelmente a importação. Augusto João Manoel Leverger comunicava, que a produção de sal, devido às inundações do rio Paraguai, havia caído tanto que o alqueire de sal chegava a custar $200 \$ 00^{39}$.

${ }^{36} \mathrm{D}$ 'Alincort, Luiz. Officio contendo notícias interessantes sobre a parte meridional da província de Matto-Grosso. Revista do Instituto Histórico e Geográfico Brasileiro, Rio de Janeiro, v. 20, p. $142,1857$.

${ }^{37}$ Discurso recitado do Vice-Presidente da Província de Matto-Grosso RIBEIRO, Manoel Alves. [Discurso] 3 maio 1848, Abertura da Sessão Ordinária da Assembléia Legislativa Provincial [manuscrito] Cuyabá. Cuiabá, Typ. Provincial, 1848. f. 13-14.

${ }^{38}$ Relatório do Presidente da Província o Major OLIVEIRA, Joaquim José de. [Relatório] 3 maio 1849, Abertura da assembléia Legislativa Provincial. [manuscrito] Rio de Janeiro. Rio de Janeiro, Typ. Imperial e Const. de J. Villeneuve e comp. 1850. f. 15.

${ }^{39}$ Relatório do Presidente da Província de Matto-Grosso o Capitão de Fragata LEVERGER, Augusto João Manoel. [Relatório] 10 maio 1851, Abertura da Sessão Ordinária da Assembléia Legislativa Provincial, [manuscrito] Cuyabá, typ. do Echo Cuiabano, 1852, f. 13. 


\section{Extrativismo vegetal \\ 2.1 Poaia}

Dentre os produtos do extrativismo vegetal, destacamos uma matéria-prima que passou a ser explorada em grande quantidade na Província de Mato Grosso, a poaia. Segundo Miranda, esse tubérculo esverdeado, encontrado no vale do rio Paraguai, entre os anos de 1837 e 1854, foi bastante procurado no mercado externo $^{40}$. As árvores podiam ser achadas em grandes proporções, sendo um dos seus principais coletores Francisco Pinto de Arruda, que todos os anos preparava importantes comitivas para colher o produto ${ }^{41}$.

Para o comerciante Joaquim Ferreira Moutinho, a poaia se constituiu na grande esperança comercial das autoridades mato-grossenses desde o início do século XIX, pois se colocava entre os produtos que, demandados pelo mercado internacional, proporcionaram um aumento na arrecadação de im$\operatorname{postos}^{42}$. Em razão de sua crescente valorização comercial, em abril de 1853, foi decretada a Lei Provincial n. 4, que estabelecia o primeiro imposto sobre a exploração e exportação da planta. A partir daí, a poaia nunca mais deixou de figurar nos orçamentos públicos da Província de Mato Grosso ${ }^{43}$. Todavia, a extração desordenada provocou prejuízos à manutenção da exploração, pois só se aproveitavam as raízes, sendo queimado o restante ${ }^{44}$. No intuíto de regular a extração da poaia, algumas medidas foram tomadas, estimulando o seu cultivo na Província de forma organizada e estratégica. Seguem comentários a respeito de uma dessas medidas.

\footnotetext{
${ }^{40}$ A exportação da Província de Mato Grosso, no ano de 1837, atingiu aproximadamente 25.000 arrobas de poaia, cita CASTELNAU, Francis de la Porte. Expedições às regiões centrais da América do Sul. São Paulo: Nacional, 1949, p. 38-39. Mais sobre o assunto ver MIRANDA, Gracy Ourives. Poaia, ipeca, ipecacuanha: poaia - uma riqueza descoberta em Mato Grosso. Revista da Universidade Federal de Mato Grosso, Cuiabá, v. 3, n. 3, set./dez. 1983, p.54-60.

${ }^{41}$ PITALUGA, Otávio. Necessidades e vantagens da proteção da poaia. Cuiabá, Instituto Histórico e Geográfico de Mato Grosso, v. 2, n. 2, 1977, p. 14-22.

${ }^{42}$ MOUTINHO, Joaquim Ferreira. Op. cit., p. 27. Ver também ADDOR, Arnaldo Augusto. Considerações acerca da poaia. Rio de Janeiro, Serviço de Informação Agrícola, 1947, p. 35.

${ }^{43}$ Veja-se, ainda, REYNALDO, Ney Iared. Comércio e navegação no rio Paraguai (1870-1940). Cuiabá: Editora da Universidade Federal de Mato Grosso, 2004. p. 146.

${ }^{44}$ CUNHA Adolpho Jorge da. O poaieiro de Mato Grosso. São Paulo: Resenha Tributária, 1981, p. 98.
} 
A mais importante destas medidas era a instituição de um prêmio em benefício de cada indivíduo ou empresas que cultivasse sistematicamente poaia nas terras de matas banhadas pelo rio Paraguay, seus afluentes ou subafluentes, em áreas não menor de quatro hectares e nunca superior a dez e que a cada hectares nunca tivesse menos de 100.000 pés de poaia ${ }^{45}$.

A produção da poaia estava dirigida na sua totalidade para o comércio internacional, em 1854, o presidente, Augusto Leverger, chamava a atenção sobre este dado: "A poaia, já constitue um verdadeiro ramo da indústria e tem dado bons resultados sendo exportada para Europa"46.

O movimento comercial da poaia mato-grossense apresentou um alto crescimento de volume, bem como o seu valor no mercado platino, conforme demonstrado na tabela 2. Nesse período, os valores foram bastante animadores, saindo 38:776\$000 (trinta e oito mil e setecentos e setenta e seis contos de réis), em 1852, para 669:511 $\$ 000^{47}$ dois anos depois, aumento que se deve ao fato de a Argentina passar a importar o produto mato-grossense.

Tabela 2 - Exportação de poaia de Mato Grosso para o mercado platino

\begin{tabular}{|c|c|c|c|}
\hline Ano & Quantidade $(\mathrm{Kg})$ & Valor (mil réis) & Mercado \\
\hline 1852 & 21.670 & $38: 776 \$ 000$ & Paraguai \\
\hline 1853 & 49.671 & $53: 921 \$ 000$ & Paraguai \\
\hline 1854 & 68.790 & $669: 511 \$ 000$ & Argentina \\
\hline
\end{tabular}

Fonte: THIÉBLOT, Marcel. Op.cit., p. 177.

Em 1854, o Governo de Mato Grosso impôs o percentual de 10\% sobre a exportação de cada arroba ${ }^{48}$, pois a exploração da poaia tinha aumentado consideravelmente. Com esta medida, a administração pública tentava aumentar a arrecadação dos impostos.

A exportação da poaia se realizou até os primeiros anos do século XX; logo depois, a planta começou a se extinguir, além do que já não era requerida pelos

${ }^{45}$ Ver, ainda, IPECACUANHA. O Observador Econômico e Financeiro, São Paulo, ano 8, n. 92, set. 1943 , p. 109.

${ }^{46}$ Relatório do presidente da Província de Mato Grosso o Capitão de Mar e Guerra. LEVERGER, Augusto João Manoel. [Relatório] 1854 maio 3, Abertura da Sessão Ordinária da Assembléia Legislativa Provincial [manuscrito]. Cuyabá. Cuiabá, Typ. do Echo Cuiabano, 1854. f. 71.

${ }^{47}$ THIÉBLOT, Marcel. A mata da poaia e os poaieiros do Mato Grosso. São Paulo: Escola do Folclore/Livramento, 1980. p. 79-82.

${ }^{48}$ Relatório do presidente da Província de Mato Grosso o Capitão de Mar e Guerra. LEVERGER, Augusto João Manoel. [Relatório] 1854 maio 3, Abertura da Sessão Ordinária da Assembléia Legislativa Provincial [manuscrito]. Cuyabá. Cuiabá, Typ. do Echo Cuiabano, 1854. f. 28. 
laboratórios farmacológicos europeus, que tinham descoberto outras drogas que foram utilizadas em seu lugar.

\subsection{Madeira}

A madeira, na região do vale do rio Paraguai, era explorada desde a época colonial. Em 1854, Augusto João Manoel Leverger deixou claro, porém, sua preocupação com a conservação das reservas madeireiras do território mato-grossense, relatando o desperdício anual na utilização das madeiras para construção de embarcações fluviais, oferecia propostas e sugestões para o estabelecimento de medidas, visando à sua preservação ${ }^{49}$. O que preocupava, também, o Ministério da Marinha, pelo seu alto preço ${ }^{50}$.

A necessidade de aproveitar economicamente as madeiras existentes em Mato Grosso era considerada importante e necessária por Augusto Leverger, mas ele ressaltava seu desejo de aguardar a execução da Lei de Terras, decretada em 1850, para tomar medidas nesse sentido e estabelecer o modo como se poderia fazer o aproveitamento racional das áreas florestais. Julgava suficiente que, naquele momento, o Governo da Província estendesse a outras matas, situadas em terrenos devolutos, as medidas tomadas às matas do Cabaçal e Sepotuba, afluentes do rio Paraguai, nas quais a extração das madeiras só era permitida, mediante licença da Presidência da Província, proibindo, nas matas reservadas, o estabelecimento de roças e a retirada indiscriminada de pequenas toras para atender aos vapores que por ali passassem. Além disso, eram tomadas algumas precauções para evitar as queimadas ${ }^{51}$.

Em 1853, o mesmo presidente Augusto Leverger, ao responder à solicitação do ministro da Marinha que desejava informações sobre as madeiras existentes

\footnotetext{
${ }^{49}$ LEVERGER, Augusto João Manoel. [Relatório] 1854 maio 3, Abertura da Sessão Ordinária da Assembléia Legislativa Provincial [manuscrito] Cuyabá. Cuiabá, Typ. do Echo Cuiabano, 1854. p. 11-14.

${ }^{50}$ Ministro da Marinha, [Ofício], Joaquim José Rodrigues Torres, ao Presidente da Província de Mato Grosso Zeferino Pimentel Moreira Freire. Rio de Janeiro, 12 dezembro de 1843. APMT. Livro 71. Registro de Avisos expedidos pelo Ministério da Marinha (1842-1853). p. 9 v.

${ }^{51}$ Condições administrativas da Província de Matto-Grosso apresentadas em Relatório de 13 de janeiro de 1850 ao Ministro e Secretário de Estado dos Negócios do Império, pelo presidente. LEVERGER, Augusto João Manuel. [Relatório]. In: O Archivo. Várzea Grande: Fundação Júlio Campos, 1993; p. 141. (Coleção Fac-similar completa 1904/1906).
} 
na região, especialmente as apropriadas para a exportação e construção naval, destacou o vale do Rio Paraguai, onde eram mais abundantes as madeiras de lei:

há matas abundantes de madeira de lei; estas acham-se também nas margens do rio Paraguai pelo lado direito. Apesar dessa fartura pouco podem por ora aproveitar-se por causa da grande distância em que estão de Villa Albuquerque [Corumbá]. Na proximidade, porém da dita povoação estão às barras do Sepotuba e do Cabaçal, que igualmente afluem pelo lado direito e correm ambos por matas ricas de madeira de construção próprias para reparos de embarcações e que se estendem até prenderem-se à grande floresta, donde esta Província tirou seu nome ${ }^{52}$.

Afirmava, ainda, que, percorrendo as margens do rio Paraguai, especialmente nas proximidades com a República do Paraguai, havia muitos terrenos que não estavam sujeitos à inundação, com matas que poderiam ser aproveitadas. entretanto, como nesta área concentrava-se a maior parte da população da Província, a retirada de madeira para atender às necessidades da lavoura e para construções já abriria muitas clareiras, e as árvores encontravam-se distantes do rio.

As medidas governamentais de preservação pouco valeram para impedir que parte dessa madeira deixasse clandestinamente a Província de Mato Grosso, com destino ao mercado platino. Nesse sentido, encontramos a documentação relativa do vapor Coxipó em 30 de novembro de 1854. Apesar de estar transportando madeira nativa, não havia qualquer registro de procedência ou destino da mercadoria na embarcação que levou o vapor a ser detido pela Marinha paraguaia, nas proximidades de Assunção e ser devolvido à Província, porém sem o carregamento da madeira que ficou no Paraguai como forma de pagamento indenizatório, imposto pelas autoridades daquele país ${ }^{53}$.

A partir de 1854, muitas dessas descobertas de diferentes tipos de madeira de lei se deram pela iniciativa privada, pois com o aumento da demanda dos

\footnotetext{
52 “Informação prestada pelo presidente da Província de Matto-Grosso, Augusto João Manoel Leverger, ao Ministro da Marinha, em 1853, sobre as mattas de madeira de construção naval". LEVERGER, Augusto João Manoel. [Informação]. In: $O$ Archivo. Várzea Grande, Fundação Júlio Campos, 1993. p. 140. (coleção Fac-similar completa 1904/1906).

${ }^{53}$ Motivo que provocou a prisão do comandante Antônio Trindade da Silva em Cuiabá, não pelo fato de conduzir madeira ilegal na fronteira, mas sim de não ter reagido à intervenção paraguaia no momento da abordagem da embarcação. Onde faz referência à madeira transportada e à abordagem paraguaia, no rio Paraguai. SILVA, Antônio Trindade da. Diário de bordo do vapor Coxipó, 1854 nov. 30, Cuyabá. Localização: Arquivo Público do Estado de Mato Grosso. Pasta 12. Lata J, (1854). Manifestos de embarcações.
} 
produtos, suas expansões e produções, o comércio e a distribuição tornaram-se cada vez mais lucrativas no mercado regional da Província de Mato Grosso com outras províncias e internacional com relação aos mercados platinos.

\subsection{Erva-mate}

A erva-mate em Mato Grosso foi outro produto extrativo de valor comercial exportador importante desse período. Em 1852, sua área de produção abrangia respectivamente parte do território paraguaio e da Província de Mato Grosso, daí a razão de o Governo Provincial criar uma Comissão que teve por objetivo fazer um levantamento das áreas produtoras de ervais na fronteira com o Paraguai.

Esta Comissão ficou sob as ordens do Coronel Antonio da Silva Salgueiro, comandante do forte de Coimbra. As tropas de apoio estavam sob a responsabilidade de Rodolfo Maria de Oliveira, importante político mato-grossense. Os dois se tornaram os primeiros protagonistas do monopólio sobre os ervais de Mato Grosso $^{54}$.

Em 1854, quando, a Comissão terminou seus trabalhos e devido ao atraso nos pagamentos por parte do Governo Provincial, o comerciante Antônio César de Oliveira fez um acordo e recebeu do Governo da Província de Mato Grosso uma boa quantidade de terras, onde iniciou o cultivo da erva-mate, juntamente com carretas e os bois, o que lhe permitiu continuar comercializando na região $0^{55}$.

São poucos os dados que existem a respeito desse comerciante. Segundo Rubens de Aquino, o que se pode dizer é que Antônio César de Oliveira teria contado com a colaboração de dissidentes paraguaios (contrários à política de Carlos Antonio López) para organizar seus trabalhos de exportação da erva-mate no sul da Província ${ }^{56}$. A sede de sua empresa estava localizada em Corumbá, no

\footnotetext{
${ }^{54}$ Ver BIANCHINI, Odália da Conceição Diniz. A Companhia Matte Larangeira e a ocupação da terra do sul de Mato Grosso: 1890-1940. 1994. f. 153. Tese (Doutorado em História). Universidade Federal Fluminense, Niterói, 1994.

${ }^{55} \mathrm{O}$ comerciante português Antônio César de Oliveira foi mascate e esteve na província nos anos de 1854-1858. Trabalhou no Mato Grosso e São Paulo, chegando a fazer transações comerciais até no Paraguai.

${ }^{56}$ Ver AQUINO, Rubens de. Tereré. In: Ciclo da erva-mate. Campo Grande: Instituto Euvaldo Lodi, 1986. p. 339.
} 
rio Paraguai. Teodoro Linhares afirma que "a erva era transportada em carretas e bois até Concepción, de onde seguia, por via fluvial, para a Argentina" ${ }^{57}$, promovendo na prática uma verdadeira "corrida" de terras para o sul de Mato Grosso motivada pela Lei n. 601, mais conhecida por Lei de Terras ${ }^{58}$.

Quando Augusto Leverger assumiu o Governo de Mato Grosso, em 1854, César de Oliveira aproveitou para manifestar seus desejos de obter mais terras na fronteira com o Paraguai para explorá-las. Baseava-se no Decreto Provincial n. 322, datado em Cuiabá, em 15 de agosto de 1854, que concedia o direito de exploração da erva-mate nos terrenos devolutos ${ }^{59}$. Este fato foi confirmado com a assinatura dos Contratos de Arrendamento com a Província de Mato Grosso. O contrato estabelecia:

Cláusula I: É concedida a Antônio Cavassa permissão por vinte annos para colher matte nos hervaes existentes nos limites da Província de Matto-Grosso com a República do Paraguay, no perímetro comprehendido pelos morros do Rincão de Julho e as cabeceiras do Iguatemy, ou entre os rios amambahy e Verde, e pela linha que de esses pontos fôr levada para o interior, na extensão de quarenta quilômetros ${ }^{60}$.

Nesse Decreto, não só foram concedidas as terras solicitadas, como também foram reconhecidos os pedidos feitos ao Governo Imperial, para que todas as concessões fossem incorporadas, estendendo, no término de dez anos, os prazos sobre as concessões obtidas nos contratos anteriores. Também era estabelecido que setenta novos trabalhadores deveriam ser incorporados aos 150 das outras concessões. Esclarecemos que os trabalhadores empregados eram mato-grossenses e paraguaios, reconhecidos pelos seus conhecimentos básicos no manejo da erva-mate.

O decreto também previa que a empresa deveria declarar, nas estações fiscais de Amambaí e Maracaju, a quantidade de sacolas de erva a exportar, deven-

\footnotetext{
${ }^{57}$ Cf. LINHARES, Teodoro. História econômica do mate. Rio de Janeiro: José Olímpio, 1969.

${ }^{58}$ GADELHA, Regina M. D`Aquino Fonseca. A Lei de Terra (1850) e a abolição da escravidão, capitalismo e força de trabalho no Brasil do século XIX. Revista de História, São Paulo, n. 120, jan./jul. 1989, p. 153-162.

${ }^{59}$ Sobre esse assunto ver SILVA, Ligia Osório. Terras devolutas e latifundiário: efeitos da Lei de Terras de 1850. Campinas: Editora da Universidade de Campinas, 1996.

${ }^{60}$ MATO GROSSO. Decreto n. 322, de 15 de agosto de 1854. Coleção das Leis e Decretos da Província de Mato Grosso, t. 15, pt. 2, v. 2, p. 531, 1854.
} 
do construir um porto na Província de Mato Grosso, em um prazo de dois anos. Até que a obra estivesse concluída, a erva seria exportada para Buenos Aires pelo porto de Concepción, localizado no Paraguai. Segundo Corrêa Filho (1957), por esse decreto César de Oliveira se comprometia em produzir anualmente quinhentos mil quilogramas ou cinquenta mil arrobas de erva-mate ${ }^{61}$.

Em 13 de outubro de 1854, a Assembléia Legislativa Provincial de Mato Grosso aprovou a Lei n. 12, que foi proposta pelo presidente da Província Augusto Leverger. Essa Lei abria a possibilidade de que outras pessoas apresentassem propostas para arrendar a exploração da erva-mate ${ }^{62}$, possibilitando que influentes políticos mato-grossenses, entre eles Albano de Sousa Osório (1857-1858), Joaquim Raymundo de Lamare (1857-1859) e Antônio Pedro D'Alencastro (1834-1836); (1859-1862), investissem na produção e exportação do mate da região, para o mercado platino ${ }^{63}$.

Todas as concessões feitas para explorar os ervais localizados ao sul de Mato Grosso eram realizadas em áreas conhecidas como terras devolutas. Essa foi uma característica própria da exploração da erva-mate. As concessões foram feitas a uma só pessoa. Borges afirma que Antônio César de Oliveira; "nunca chegou ter a posse de terra, pois as mesmas pertenciam à Província de Mato Grosso, o qual poderia dispor das mesmas como acreditasse mais conveniente, uma vez terminado o prazo de concessão ${ }^{64}$.

O concessionário teve certas vantagens, pois não precisou investir capital para receber lucros, não necessitou plantar, nem esperar as plantas se desenvolverem, porque as plantas de erva-mate eram naturais e estavam prontas para ser exploradas; também não investiu capital para comprar terras. O capital investido foi utilizado na contratação de trabalhadores paraguaios e para abrir caminhos, construir portos e depósitos, pois os ervais se encontravam em zonas quase não ocupadas, com vias de comunicação quase inexistentes. Pelas próprias caracte-

${ }^{61}$ CORRÊA FILHO, Virgílio. Ervais do Brasil e ervateiros. Rio de Janeiro, Serviço de Informação Agrícola, 1957. p.12.

${ }^{62}$ ARRUDA, Gilmar. Heródoto. In: Ciclo da erva-mate. Campo Grande: Instituto Euvaldo Lodi, 1986. p. 281.

${ }^{63}$ PÓVOAS, Lenine de Campos. Influência do Rio da Prata em Mato Grosso. São Paulo: Resenha Tributária, 1982. p. 24.

${ }^{64}$ BORGES, Fernando Tadeu de Miranda. Op. cit. 
rísticas do produto, a erva-mate devia ser exportada com maior rapidez possível com o objetivo de ser industrializada.

Marques diz que as exportações de mate do Mato Grosso eram realizadas pelo Porto Murtinho, na margem esquerda do rio Paraguai. A área de exploração foi aumentada pela Resolução n. 103, de 15 de dezembro de 1854, que estabelecia novos arrendamentos. Estamos diante de um fenômeno econômico pouco comum na América Latina, na segunda metade do século XIX, pois falamos de uma empresa que sofreu diversos processos de organização e transformação internas ${ }^{65}$.

\subsection{Aagroindústria açucareira}

Desde os primórdios da colonização de Mato Grosso, tem-se registro da presença de engenhos açucareiros que produziam açúcar, rapadura, melado e aguardente para abastecer os povoados que surgiram. Há referências a partir de $1728^{66}$ e no início do século XIX o engenho Tamandaré de propriedade de Antonio Joaquim M. Serra em 1818.

Com a abertura da navegação do rio Paraguai em 1853, a agroindústria açucareira continuou sua expansão em Mato Grosso, facilitada pela entrada de novas tecnologias compradas na Europa e provocou um aumento na produção de açúcar branco. Tal produção começou a ser exportada para o Paraguai. Segundo Corrêa Filho (1994), esses canaviais eram irrigados pelas enchentes do rio Paraguai, que anualmente colaboravam na fertilização do solo ${ }^{67}$. Nem todos os engenhos na Província fabricavam açúcar branco, produzindo a maioria deles rapadura e aguardente, o único que tinha máquinas a vapor era o de Joaquim Paes de Barros, enquanto os outros utilizavam uma tecnologia antiga: a moenda de ferro.

\footnotetext{
${ }^{65}$ MARQUES, Antônio. A província de Mato-Grosso: recursos naturaes. Rio de Janeiro: Americana, 1946. p. 144-156.

${ }^{66}$ Segundo CORRÊA FILHO, Virgílio. História de Mato Grosso. Várzea Grande: Fundação Julio Campos, 1994. p. 12-13, em 1726, Antônio de Almeida Lara já havia obtido sesmarias na Chapada, distante dois dias de Cuiabá, onde já tinha começado a produção de açúcar e especialmente de aguardente.

${ }^{67}$ Relatório do presidente da Província de Mato Grosso o Capitão de Mar e Guerra. LEVERGER, Augusto João Manoel. [Relatório] 1854 maio 3, Abertura da Sessão Ordinária da Assembléia Legislativa Provincial [manuscrito] Cuyabá. Cuiabá, Typ. do Echo Cuiabano, 1854. p. 43.
} 
Em 1854, eram registrados três engenhos de açúcar e aguardente em Mato Grosso que utilizavam máquinas movidas a vapor. Estes engenhos pertenciam a Antônio Manoel da Silva, Casário Corrêa da Costa, Joaquim Paes de Barros, e estavam localizados ao longo do rio Cuiabá ${ }^{8}$. O engenho localizado em Corumbá pertencia a Maximiliano Romão Cárcano e o de São Luiz de Cáceres, a José de Pinho ${ }^{69}$.

Esses engenhos mato-grossenses de cana-de-açúcar, logo se beneficiaram com a abertura da navegação do rio Paraguai, o que permitiu que maquinarias a vapor fossem compradas e instaladas, transformando-as em pequenas usinas açucareiras $^{70}$. A produção desses estabelecimentos era comercializada no mercado regional, permitindo o autoabastecimento de açúcar, aguardente e rapadura, sendo os excedentes exportados para a república vizinha do Paraguai ${ }^{71}$.

Com a abertura da navegação, em Buenos Aires, Antônio Paes assinou um contrato com Otto Franke, pelo qual o comerciante argentino concedia empréstimo para instalar uma fábrica de açúcar e aguardente em Corumbá, na Província de Mato Grosso em fins de 1853. as máquinas vieram da Alemanha e o pagamento foi feito com a própria produção ${ }^{72}$. Já em 1854, o português cronista Moutinho em sua Notícia sobre a Província de Mato Grosso, nos oferece dados precisos relacionados ao total de engenhos existentes na Província de Mato Grosso na época e assegura que eram cento e cinquenta e três ${ }^{73}$.

A instalação dessa pequena usina significou um grande investimento de capital na época, não somente para comprar as máquinas, como também para a construção predial e contratação de técnicos e mão de obra qualificada. O processo de produção passou por variações tanto na qualidade quanto na quantidade de açúcar. priorizando a rapidez no transporte da cana, a usina utilizava embar-

${ }^{68}$ Ibid., p. 61.

${ }^{69}$ PÓVOAS, Lenine de Campos. O ciclo do açúcar e a política de Mato Grosso. São Paulo: Resenha Tributária, 1982. p. 53.

${ }^{70}$ CORRÊA FILHO, Virgílio. A indústria açucareira em Mato Grosso. Rio de Janeiro: Brasil Açucareiro, 1841. p. 139.

${ }^{71} \mathrm{O}$ Governo Provincial arrecadava $15 \%$ sobre a venda da aguardente exportada para o Paraguai.

${ }^{72}$ MENDONÇA, Estevão de. Quadro corográfico de Mato Grosso. Cuiabá: Escolas profissionais salesianas, 1906, p. 121.

${ }^{73}$ MOUTINHO, Joaquim Ferreira. Op. cit. 
cações a vapor e barcaças que percorriam o rio Paraguai em direção ao Prata ${ }^{74}$.

\section{As fazendas de gado da provincia de Mato Grosso}

De todo os setores da economia de Mato Grosso aquele que mais se expandiu e consolidou foi o da pecuária ${ }^{75}$. Iniciou-se por volta de 1737, com a chegada dos primeiros rebanhos ${ }^{76}$. Como se percebe a pecuária baseada na caça ao gado já era praticada em Mato Grosso durante o período colonial, devido às pastagens naturais da província e pouca demanda de mão de obra. Ronco (2006) e Silva (2005), concordam que o maior desenvolvimento da pecuária em Mato Grosso ocorrera nas primeiras décadas do século XIX, já no decênio de 1820 em diante, quando do surgimento das primeiras fazendas de gado na região foi favorecido, inicialmente, pela instalação da Corte no Rio de Janeiro (1808), já que, com o significativo aumento demográfico que experimentou essa cidade, cresceu a demanda por produtos pecuários ${ }^{77}$.

Diferentemente da exploração mineral, a produção pecuária é renovável e não necessita de vultosos investimentos para seu desenvolvimento. Essas ca-

${ }^{74}$ Cf. MENDONÇA, Rubens de. História do comércio de Mato Grosso. Goiânia: Rio Bonito, 1974. Para saber mais, ver Mappa Econômico que comprehende o estado actual da agricultura e minas desta Capitania como também os offícios mecânicos e produção de gado vacum e cavalar calculado desde o anno de 1769 a 1770 . Primeiro da Administração do Capitão-general Luiz Pinto de Souza. (MF-215 doc. 2470 - Arquivo Nacional - Rio de Janeiro).

${ }^{75}$ Sobre esse tipo animal, há que considerar que, na primeira metade do século XVII, algumas cabeças de gado bovino foram introduzidas na povoação castelhana de Xerez, nas cabeceiras do rio Aquidauana. A destruição de Xerez pelos paulistas deu origem ao gado bravio, que proliferou pelos campos selvagens do Pantanal e passou a ser conhecido por gado alçado. O historiador Virgílio Corrêa Filho supunha que desse gado semisselvagem teriam sido levadas às primeiras matrizes para a fazenda de Camapuã e, depois, para Cuiabá; é esta a versão provável da origem do gado bovino mato-grossense . CORRÊA FILHO, Virgílio. A propósito do boi pantaneiro. São Paulo: Pongetti, 1926. p. 21.

${ }^{76}$ FIGUEIREDO, Aline. A propósito do boi. Cuiabá: Editora da Universidade Federal de Mato Grosso, 1994. p. 105.

${ }^{77}$ RONCO, Adriana Patrícia. Op. cit.. Ver, também MAMIGONIAN, Armen. Inserção de Mato Grosso ao mercado nacional e a gênese de Corumbá. Geosul - Revista do Departamento de Geociências da UFSC, Florianópolis, n. 1, p. 39-53, 1. sem. 1986. p. 51. SILVA, Jovam Vilela da. Histórico da pecuária no Brasil: Fator de integração e desenvolvimento. Cuiabá: KCM, 2005. p. 65. 
racterísticas fizeram o próprio Estado fundar, nos anos de 1854 e 1855, fazendas públicas em Aquidauana, Coimbra, Cuiabá e Miranda. Parte do rebanho era utilizada no abastecimento dos fortes e guarnições militares recém-criados, e o restante, comercializado na região. As comitivas de gado mato-grossenses utilizavam antigo caminho terrestre de Goiás para chegar ao sul de Minas Gerais ${ }^{78}$ e, após terem percorrido uma longa viagem, eram conduzidas a fazendas de invernada, a fim de se restabelecerem e ganharem peso, para logo serem vendidas no mercado consumidor carioca.

O gado mato-grossense se adaptou ao clima de altas temperaturas, com alto percentual de umidade e á permanência, durante muito tempo, em terras alagadas. $\mathrm{O}$ couro denso tornava o gado resistente à picada de insetos e às mudanças climáticas do Pantanal. Essas características favoreceram o comércio do gado pantaneiro nos mercados das províncias de São Paulo e Minas Gerais.

$\mathrm{Na}$ fronteira da Província de Mato Grosso com o Paraguai, o rebanho cresceu e colaborou para a formação de grandes fazendas, cujas dimensões eram sempre questionáveis. Dentre as principais fazendas exportadoras de gado existentes nessa região, destacava-se a fazenda Alegre, do Major José Caetano Mertello, com 151.210 hectares nas proximidades do rio Brilhante. Em 1854, acabou sendo confiscada pelo Império em função das dívidas do proprietário

Transferida para o domínio do Império, era imenso território, de mais de meio milhão de hectares, ou mais aproximadamente 648.705 hectares, conforme os assentamentos próprios, despovoados pela matança desordenada, que transformou os seus rebanhos em extrato de carne e couro $^{79}$.

Havia, ainda, a fazenda Firme, pertencente a Joaquim Gomes da Silva, que abrangeu 175.853 hectares situados entre os rios Negro e Taquari e que foi invadida pelos paraguaios. Suas dimensões eram tão vastas que, de acordo com cálculos de Corrêa Filho (1955), na segunda metade do século XIX, houve a partilha de cem outras fazendas provenientes da original Firme ${ }^{80}$.

\footnotetext{
${ }^{78}$ CORRÊA FILHO, Virgílio. O boi pantaneiro. Instituto Histórico e Geográfico de Mato Grosso, Cuiabá, n. 59, 2002, p. 341-342. (Monografias Cuiabanas).

${ }^{79}$ CORRÊA FILHO, Virgílio. Fazendas de gado no Pantanal Mato-grossense. Rio de Janeiro: Ministério da Agricultura, 1955. p. 27.

${ }^{80}$ Idem, p. 27.
} 
Durante as administrações de Augusto Leverger, verificou-se o crescimento do latifúndio na fronteira ${ }^{81}$. O próprio presidente fez referência ao surgimento de uma dessas extensas fazendas voltadas para atender a exportação bovina na Bacia do Prata, a fazenda Jacobina, às margens do rio Paraguai de propriedade de Leonardo Soares de Sousa ${ }^{82}$. Essa foi a mais conhecida da Província de Mato Grosso. Seu rebanho bovino foi calculado, pelo Engenheiro Francisco Antônio Pimenta Bueno, em 600 mil cabeças de gado, numa área de 240 léguas $^{283}$, em 1854, chegou, inclusive, a exportar grande quantidade de animais para as praças da bacia do Rio da Prata, conforme demonstrado na tabela 3. Não há referência de outras fazendas com esse número de gado, o que comprovava sua importância para a região ${ }^{84}$.

Tabela 3 - Tipos de Gado e a quantidade exportada para Bacia do Prata (1852-1854)

\begin{tabular}{|c|c|c|c|c|}
\hline Anos & Vaca & Boi & Novilhos & Boi de Carro \\
\hline 1852 & 3.500 & 7.952 & 2.824 & 935 \\
\hline 1853 & 13.943 & 8.527 & 3.011 & - \\
\hline 1854 & 15.608 & 8.612 & - & 1.112 \\
\hline Total & 33.051 & 25.091 & 5.835 & 2.047 \\
\hline
\end{tabular}

Fonte: Anuário de registro de exportação da província de Mato Grosso. Localização: Arquivo Público do Estado de Mato Grosso

Silva destaca que, além dessa produção pecuária de gado de grande porte que era exportada para o exterior, havia também a da pequena propriedade com reduzido número de reses e de cabras, que comercializava seus animais nos açougues mato-grossenses para o consumo popular ${ }^{85}$. Esses açougues tinham por fornecedores inúmeros matadouros oficiais e clandestinos, existentes em Cuiabá,

${ }^{81}$ Relatórios Anuais do Presidente da Província de Matto-Grosso o Capitão de Fragata Augusto João Manoel Leverger, nos anos de 1851, 1852, 1853 e 1854.

${ }^{82}$ Ressalte-se que nessa época, a fazenda Jacobina já tinha começado a etapa de declínio, processo que se acentuou com a abolição da escravidão, pela falta de mão de obra, acrescentada pela má administração de Luiz Carlos Leite, a tal ponto que 880.000 hectares foram vendidos em hasta píblica para pagamento de impostos atrasados; as terras e o gado foram avaliados somente em duzentos e cinco contos. A fazenda pertenceu à família Leite por 123 anos. LEITE, Luis Carlos [Inventário patrimonial] 1854. Localização: Arquivo Público do Estado de Mato Grosso. Lata D. Pasta III.

${ }^{83}$ Cf. SILVA, Jovam Vilela da. Op. cit., p. 189.

${ }^{84}$ Para Lécio Gomes de Souza, esse número não teria ultrapassado a cifra de 200 a 300 mil cabeças. SOUZA, Lecio Gomes de. Jacobina, história de uma fazenda de Mato Grosso. Instituto Histórico Geográfico de Mato Grosso, Cuiabá, v. 1, n. 9, 1998, p. 5.

${ }^{85}$ SILVA, Jovam Vilela da. Op. cit. p. 176. 
Cáceres e Corumbá ${ }^{86}$. Em 1854, o presidente da Província, Augusto Leverger, verificando a importância que esse comércio regional tinha para a Fazenda Pública, propôs à Assembléia Legislativa Provincial uma reforma nos impostos que eram cobrados sobre os animais que circulavam em Mato Grosso. Declarava ele, acerca dos dízimos sobre a produção pecuária.

[...] entendo, pois, que será conveniente estabelecer de novo as proporções em que os dízimos devem pesar que convenha 10 por cento no gado vacum e cavalar; 5 por 100 no ovelhum e porco, de que sofremos bastante falta, 4 por 100 sobre as aves abolindo-se os dízimos intitulados de minúcias, e continuando a inserção do gado muar, criação que ora começa, e de que tanto dependemos para nossos transportes ${ }^{87}$.

Neste ano de 1854, alguns problemas comprometeram a exploração sistemática dos rebanhos da Província. Entre eles, uma tripanossomíase epizootia, mais conhecida em Mato Grosso, como o "mal ou peste das cadeiras" se tornou endêmica e responsável pela dizimação de quase $1 / 3$ dos rebanhos equinos e vacum de parte da fronteira meridional mato-grossense. Apesar desse problema, Augusto Leverger fez referência ao comércio de gado na fronteira, afirmando que era o que mais benefícios trazia a Província, pois as reses eram vendidas em mercados certos, como os das províncias de São Paulo, Goiás, Minas Gerais e República do Paraguai ${ }^{89}$.

\section{As casas comerciais de importaçãoe exportação}

Com a abertura da navegação no rio Paraguai, a partir de 1853, as casas

${ }^{86}$ LEITE, Gervásio. O gado na economia mato-grossense. Rio de Janeiro: Typ. Nacional, 1880. p. 219. ${ }^{87}$ LEVERGER, Augusto João Manoel. [Fala] 1856 maio 3 Abertura da Sessão Ordinária da Assembléia Legislativa Provincial [manuscrito] Cuyabá. Cuiabá, Typ. do Echo Cuiabano, 1856. f. 12.

${ }^{88}$ Esta doença teria surgido na ilha do Marajó entre os anos de 1827 e 1830, espalhando-se rapidamente por toda a região norte e Pantanal mato-grossense, aponta PROENÇA, M.C. Apontamentos sobre epizootiologia da peste de cadeiras em Mato Grosso. Revista Militar de Medicina Veterinária, Rio de Janeiro, v. 11, n. 19, p. 1.413-1.421, out./nov. 2002. Em Mato Grosso, o sintoma principal era a paralisia dos membros posteriores dos animais. Cf. CORREAA FILHO, Virgílio. $A$ febre das cadeiras. Revista do Instituto Histórico Geográfico de Mato Grosso, Cuiabá, v. 31, n. 59, p. 401, jan./jun. 2002. (Monografias Cuiabanas).

${ }^{89}$ Sobre essa exportação ao Paraguai ver AYALA, S. Cardoso; SIMON, F. (Org.). Álbum graphico do Estado de Matto-Grosso. Corumbá: Hamburgo, 1914. p. 131. 
comerciais de importação e exportação constituíram-se no centro dinâmico da região do Prata. Foram instrumento indispensável à consolidação e acumulação de capital inglês na Província, pois elas importavam, distribuíam e comercializavam as mercadorias manufaturadas fora do país e exportavam e produziam os produtos primários locais, muitas vezes para o exterior ${ }^{90}$.

Porém, diferentemente desse modelo clássico, a casa comercial mato-grossense surgiu dos recursos capitalizados internamente a partir da exploração mineira, do comércio monçoeiro, de uma pecuária em expansão e da indústria extrativa, À medida que transacionavam os produtos regionais entre si e com o exterior, também traziam dos países industrializados as principais manufaturas.

Alves informa que "a peculiaridade da operação de compra e venda nas casas comerciais da Província de Mato Grosso consistia em que ela só se efetivava mediante a presença física da mercadoria" "91. Para que se entenda a razão disso, é indispensável destacar duas questões relacionadas a essa operação: a primeira reside no fato de que o pagamento só se fazia mediante a entrega do produto, daí por que as operações de crédito eram desconhecidas ou tinham pequena importância por seu insignificante volume ${ }^{92}$; a segunda está em que a qualidade do produto ainda não apresentava, naquela fase, uma padronização. Logo, o preço acertado na compra e na venda se encontrava sempre na dependência do nível da qualidade da mercadoria que estava sendo comercializada, o que tornava indispensável a presença desta.

A organização dessas casas comerciais na Província de Mato Grosso remonta ao início do século XIX. Até esse período, havia diversos estabelecimentos na Província que concentravam o movimento comercial e financeiro da região: "havia trinta lojas de fazendas e de secos e molhados em Cuiabá e dezesseis em Corumbá, “foram os 'boliches' e botecos (tabernas), incumbidos de movimentar o comércio e onde os mineradores gastavam grande parte do ouro que coletavam

\footnotetext{
${ }^{90}$ ALVES, Gilberto Luiz. Mato Grosso e a História: 1870-1929 (Ensaio sobre a transição do domínio econômico da casa comercial para a hegemonia do capital financeiro). Boletim Paulista de Geografia, São Paulo, v. 2, n. 6, set./dez. 1984, p. 5-81.

${ }^{91}$ Idem., p. 132.

${ }^{92}$ Idem., p. 65.
} 
durante o dia",93.

Os primeiros comerciantes mato-grossenses proprietários dessas casas comerciais submeteram a economia regional ao seu controle. Para isso, montaram uma rede de coleta de informações relacionadas ao preço, tipo do produto, condições de produção, etc, processo no qual contavam com o concurso de homens de confiança, os mascates ${ }^{94}$.

Siqueira informa que estes mascates começaram a percorrer áreas distantes da província, oferecendo, a alto preço, suas mercadorias e recebendo em troca, o pouco meio circulante existente ou a baixo custo, a produção de cada região que visitavam. A maioria dos mascates ou caixeiros-viajantes estava a serviço de uma casa comercial ou de um grande comerciante instalado nas cidades ${ }^{95}$.

Existiram, na Província de Mato Grosso, dois tipos de mascates: os que percorriam o território por terra e os que o faziam pelos rios. Os primeiros conhecidos por mascates tropeiros, procedentes das províncias de São Paulo, Minas Gerais e Goiás, seguiam os caminhos terrestres abertos (antigas trilhas indígenas), conduzindo suas mercadorias em lombo de mulas. Os mascates fluviais acompanhavam os principais cursos dos rios, trazendo seus produtos para serem comercializados por toda a Província. Para Corrêa, esse tipo de mascate, ia além de seu papel imediato, pois sua circulação na Província

[...] permitiu também maior conhecimento da região, coletando informações sobre suas potencialidades econômicas, suas terras e riquezas minerais. Esses mascates imigrantes nostálgicos da pátria distante, sem qualquer vínculo com a terra e tendo por casa sua própria embarcação, traziam enfim uma característica internacional, cujos interesses estavam ligados aos mercados externos $[\ldots]^{96}$.

Um dos mais conhecidos mascates da região sul da província foi o português Manoel Cavassa, que chegou de Buenos Aires com uma pequena carga de mercadorias, na década de 1840. Convém salientar que muitos destes mascates foram, com o tempo, instalando suas próprias casas comerciais, principalmente

\footnotetext{
${ }^{93}$ MENDONÇA, Rubens de. Op. cit., p. 20.

${ }^{94}$ SIQUEIRA, Elizabeth Madureira. História de Mato Grosso: da ancestralidade aos dias atuais. Cuiabá: Entrelinhas, 2002.

${ }^{95}$ Idem, p. 27.

${ }^{96}$ CORREAA, Valmir Batista. Mato Grosso do Sul: a fronteira oeste revisitada. Corumbá: 1974. p. 12.
} 
em Cuiabá e, posteriormente, em Corumbá. Nesse período, tal estabelecimento dispunha de acesso privilegiado aos mercados dos grandes centros platinos e brasileiros, fato que lhes possibilitava o controle dos preços das mercadorias e a informação sobre as novas tendências de consumo ${ }^{97}$.

Com o decorrer do tempo, não só comerciantes individuais percorriam a Província de Mato Grosso, como também algumas casas comerciais das províncias de São Paulo e Rio de Janeiro abriram verdadeiras sucursais nas principais cidades da Província, como Cuiabá, Cáceres e Corumbá. Segundo Corrêa Filho essas casas comerciais não estavam interessadas em procurar artigos para o intercâmbio comercial, mas visavam ao ouro que era colhido na região ${ }^{98}$. Alem disso, com o crescente aumento da pecuária no sul da Província, muitas delas passaram a investir no comércio de compra e venda de gado e de terras, formando grandes fazendas, destinadas à exportação ou ao mercado interno.

No âmbito regional, levantavam informações anuais sobre as condições ambientais que poderiam interferir na produção dos produtos, que comercializavam ${ }^{99}$. Assim, colhiam informações sobre as áreas plantadas, a respeito da influência de pragas e de variações climáticas, bem como sobre as áreas mineiras efetivamente exploradas, o número de trabalhadores escravizados envolvidos, etc. Reunindo esses informes, a casa comercial podia estimar a magnitude da produção anual de cada produto e, a partir daí, concluir sobre uma eventual superprodução ou escassez de determinadas mercadorias no mercado de consumo ${ }^{100}$. Dessa forma, o comerciante dispunha de uma clareza antecipada sobre quais produtos prometiam maiores lucros, a curto e médio prazo, nas operações de compra e venda.

Essas casas comerciais possibilitaram a recomposição do sistema comercial da Província. Destacamos suas atividades realizadas e vimos que elas iam

\footnotetext{
${ }^{97}$ Confira-se Memorandum que dirige da cidade de Corumbá, Estado do Matto-Grosso, o cidadão Manoel Cavassa ao presidente da República dos Estados Unidos do Brasil (22 de fevereiro de 1894), apud CORRÊA, Valmir Batista; CORRÊA, Lúcia Salsa. Memorandum de Manoel Cavassa. Campo Grande: Editora da Universidade Federal de Mato Grosso do Sul, 1997.

${ }^{98}$ CORRÊA FILHO, Virgílio. Indústrias mato-grossenses. Rio de Janeiro, [s.n.], 1945. p. 33. (Monografias Cuiabanas).

${ }^{99}$ ALVES, Gilberto Luiz. Mato Grosso e a História: 1870-1929 (Ensaio sobre a transição do domínio econômico da casa comercial para a hegemonia do capital financeiro). Boletim Paulista de Geografia, São Paulo, v. 2, n. 6, set./dez. 1984, p. 5-81.
}

${ }^{100}$ Idem, p. 5-81. 
muito além das funções de estabelecimento comercial. Estabeleceram também importantes intercâmbios com outras províncias, como Rio de Janeiro, São Paulo, Minas Gerais, Bahia, Goiás, Pará, e países vizinhos, como Bolívia, Paraguai, Uruguai e Argentina. 
